Conclusion Collateral grade, NIHSS score at presentation, and number of passes are independent predictors of unfavorable outcomes at 90 days.

Disclosures A. Siddiqui: 1; C; Co-investigator NIH/NINDS 1R01NS091075. 2; C; Canon Medical System US, Boston Scientific, Amnis Therapeutics, Cerebrotech Medical Systems, Silk Road, Corindus Inc., Blockade Medical, Guidepoint Global Consulting, Imperative Care, Integra LifeSciences Corp, Medtronic, MicroVention, Q’Apel Medical Inc, Rapid Medical, Rebound Therapeutics Corp., Serenity Medical Inc, Silk Road Medical, StimMed, Stryker, Three Rivers Medical, VasSol, W. L. Gore \& Associates. M. Waqas: None. T. Andersson: 2; C; Neuravi, Ablynx, Amnis Therapeutics, Medtronic, Rapid Medical, Stryker. J. Saver: 1; C; Medtronic-Abbott, Neuravi. H. Mattle: None. H. Bozorgchami: None. R. Chapot: None. A. Narata: None. A. Yoo: 1; C; Penumbra, Neuravi, Cerenovus. M. Ribo: None. O. Zaidat: 2; C; Stryker, Medtronic, Neuravi, Penumbra.

\section{0-003 PREDICTORS OF SUCCESSFUL REVASCULARIZATION IN THE ARISE II STUDY}

${ }^{1} \mathrm{~A}$ Jadhav*, ${ }^{1} \mathrm{~S}$ Desai, ${ }^{2} \mathrm{D}$ Liebeskind, ${ }^{3} \mathrm{~A}$ Yoo, ${ }^{4} \mathrm{H}$ Bozorgchami, ${ }^{5} \mathrm{M}$ Ribo, ${ }^{2} \mathrm{JL}$ Saver, ${ }^{6} \mathrm{H}$ Mattle, ${ }^{7} \mathrm{~T}$ Andersson, ${ }^{8} \mathrm{O}$ Zaidat. ${ }^{1}$ University of Pittsburgh Medical Center, Pittsburgh, $P A ;{ }^{2}$ University of California Los Angeles, Los Angeles, CA; ${ }^{3}$ Texas Stroke Institute, Plano, $T X ;{ }^{4}$ Oregon Health and Science University, Portland, OR; ${ }^{5}$ Hospital Vall $d^{\prime}$ Hebron, Barcelona, SPAIN; ${ }^{6}$ Neurologische Universitätsklinik, Inselspital, Bern, SWITZERLAND; ${ }^{7} A Z$ Groeninge, Kortrijk, BELGIUM; ${ }^{8}$ Neuroscience Institute, Mercy Health St. Vincent Medical Center, Toledo, $\mathrm{OH}$

\subsection{6/neurintsurg-2019-SNIS.3}

Introduction Swift and complete revascularization in large vessel occlusion (LVO) stroke is associated with better functional outcomes. First pass effect (FPE), achievement of TICI 2C/3 revascularization on the first pass, is a new metric of technical success of endovascular thrombectomy (EVT). We aim to identify predictors of FPE and TICI 3 revascularization in the ARISE II study.

Methods Anterior circulation LVO [ACLVO-internal carotid (ICA) and middle cerebral artery (MCA-M1)] strokes from the ARISE II study were used for this analysis. Core-lab adjudicated TICI scores after the first pass of EmboTrap were collected. FPE and modified FPE (mFPE) were defined as first pass achievement of TICI $2 \mathrm{C} / 3$ and TICI $\geq 2 \mathrm{~B}$, respectively. Demographic, clinical and radiographic parameters were analyzed. Multivariable logistic regression was performed to identify predictors.

Results A total of 161 ACLVOs underwent thrombectomy in the ARISE II study. Mean age was $67 \pm 13$ years and $43 \%$ $(n=69)$ were male. Mean NIHSS and median ASPECTS were $16 \pm 5$ and 10, respectively. While FPE was achieved in $37 \%$ $(n=59)$, mFPE was seen $43 \%(n=69)$ patients. Multivariable logistic regression was performed using age, sex, use of IVtpA, BMI, NIHSS, vascular risk factors, ASPECTS, collateral status (ASITN), occlusion location and use of balloon-guided catheter as variables. While absence of ICA occlusion $(p=0.07$, OR-8.6, 0.8-90) can predict FPE, there were no independent predictors of mFPE. Independent predictors of TICI 3 after 3 passes include use of balloon guide catheter $(\mathrm{p}=0.01$, OR-0.033, 0.003-0.535) and higher ASITN score $(\mathrm{p}=0.04$, OR-10.2, 1-100).
Conclusion Absence of internal carotid artery occlusion predicts FPE and the use of balloon guide catheter and favorable collaterals predicts complete revascularization. These results support the consideration of routine BGC use with the Embotrap device to achieve complete revascularization.

Disclosures A. Jadhav: None. S. Desai: None. D. Liebeskind: None. A. Yoo: None. H. Bozorgchami: None. M. Ribo: None. J. L: None. H. Mattle: None. T. Andersson: None. O. Zaidat: None.

\section{0-004 CHANGES IN GENE EXPRESSION OF CXCL9 IN INTRACRANIAL DISTAL BLOOD DURING EMERGENT LARGE VESSEL OCCLUSION IN HUMAN STROKE}

1J Fraser*, ${ }^{2} S$ Martha, ${ }^{2} \mathrm{~L}$ Collier, ${ }^{2} S$ Davis, ${ }^{3} \mathrm{~A}$ Alhajeri, ${ }^{4} \mathrm{~S}$ Grupke, ${ }^{2} \mathrm{~K}$ Pennypacker. ${ }^{1}$ Neurological Surgery, Neurology, Radiology, and Neuroscience, University of Kentucky, Lexington, $K Y$; ${ }^{2}$ Neurology, University of Kentucky, Lexington, $K Y ;{ }^{3}$ Neurological Surgery, Neurology, and Radiology, University of Kentucky, Lexington, $K Y_{;}{ }^{4}$ Neurological Surgery, University of Kentucky, Lexington, KY

\subsection{6/neurintsurg-2019-SNIS.4}

Background and purpose Mechanical thrombectomy (MT) is the standard of care for emergent large vessel occlusion (ELVO), one of the most severe subtypes of ischemic stroke, which accounts for $30-40 \%$ of all cases. Through MT, we can isolate distal blood within the artery immediately downstream from the clot and compare it to systemic arterial blood to provide insight into local intraluminal changes during ischemia. CXCL9 is in interferon gamma-inducible chemokine that binds CXCR3, degrading endothelial tight junctions, attracting $\mathrm{T}$ cells, and facilitating immune cell extravasation into brain parenchyma. We aimed to study local CXCL9 expression distal to the intracranial thrombus during large vessel occlusion in human patients.

Methods Tissue samples of distal and proximal blood were collected as part of the BACTRAC tissue bank (www.clinicaltrials.gov NCT03153683). Adult subjects with ELVO were prospectively enrolled, and arterial blood distal (intracranial) and proximal (cervical) were collected and processed to optimize RNA quality. RNA were isolated and used to evaluate gene expression in both samples for each subject; proximal systemic blood was used as an internal control for each subject.

Results 22 subjects were included in this preliminary analysis. $15(68.2 \%)$ were female. $54.5 \%$ of subjects had a CTA collateral score of $1(18.2 \%$ had a score of 0$) .4 .5 \%$ (1 subject) did not attain TICI $2 \mathrm{~B}$ or 3 recanalization. Infarct time (last known normal to thrombectomy recanalization) was $491 \pm 243$ minutes. Mean change in NIHSS from admission to discharge was $-8 \pm 8$. CXCL9 expression in distal blood was upregulated an average of 106-fold with a maximum upregulation of 805 -fold in one subject. In plotting CXCL9 expression against infarct time, there was a clear negative correlation (Spearman coefficient -0.43, $\mathrm{p}=0.05)$.

Conclusion For the first time, we evaluate chemokine alterations in human stroke patients in distal stagnant blood during ELVO. There is a significant variance in CXCL9 expression in distal blood in relationship to infarct time, which mirrors the known timing of blood-brain barrier disruption. 


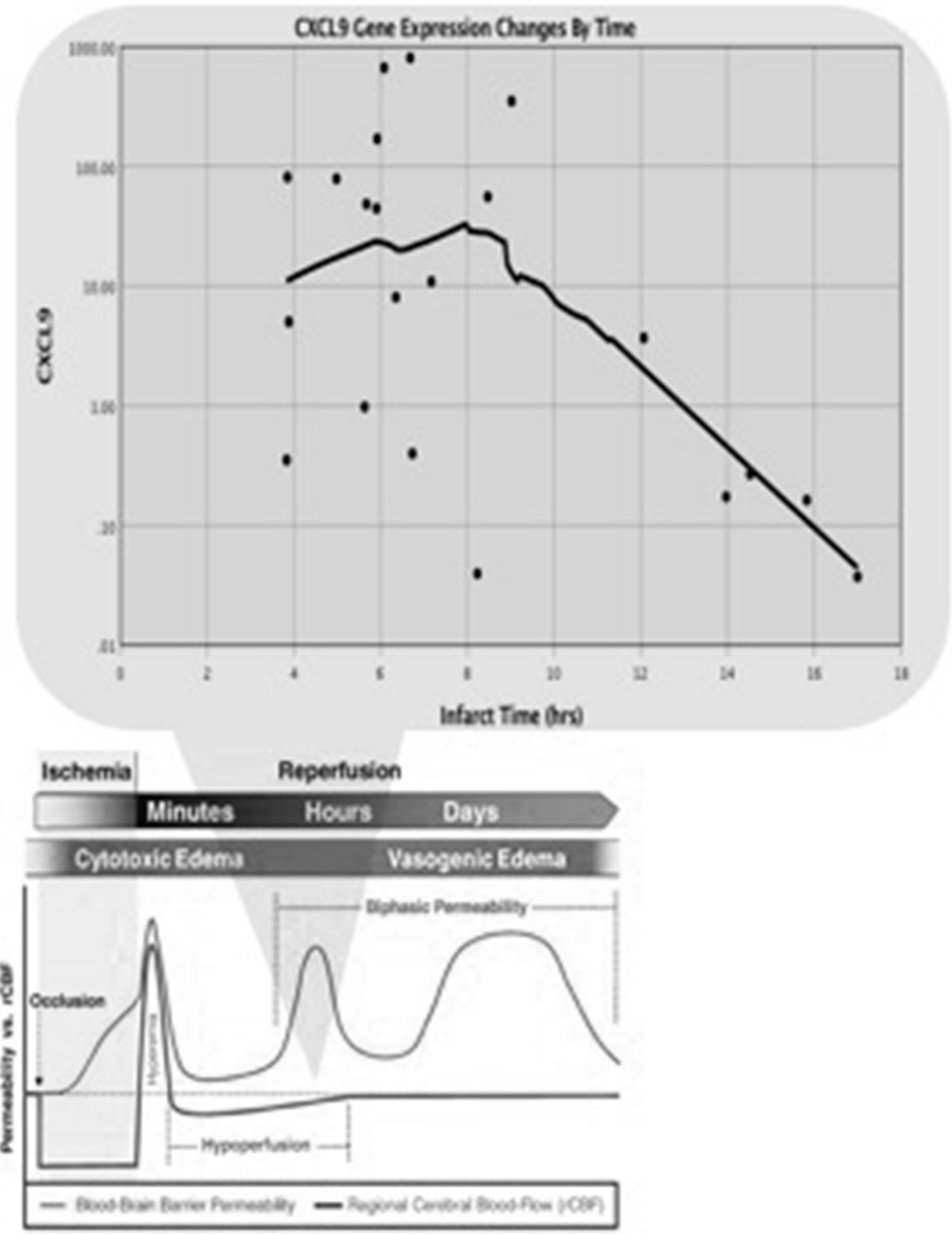

Abstract 0-004 Figure 1 Graph demonstrating time-dependent differential gene expression of CXCL9 in distal vs proximal blood sample ( $\mathrm{n}=21$ ). The $y$-axis shows fold-changes in distal expression over proximal expression. Infarct time is defined as Last Known Normal to thrombectomy recanalization moment. The panel below shows these changes mapped to a published timeline of BBB permeability

Disclosures J. Fraser: None. S. Martha: None. L. Collier: None. S. Davis: None. A. Alhajeri: None. S. Grupke: None. K. Pennypacker: None.

\section{O-005 THE IMPACT OF FAILED REPERFUSION ON THE CLINCAL OUTCOMES OF PATIENTS PRESENTING WITH LOW NIHSS LARGE VESSEL OCCLUSION}

F Chin*, M Waqas, H Shallwani, H Rai, E Lewy, A Siddiqui. Endovascular Neurosurgery, SUNY Buffalo, Buffalo, NY

\subsection{6/neurintsurg-2019-SNIS.5}

Introduction The effectiveness of mechanical thrombectomy in patients presenting with a low NIHSS and large vessel occlusion is uncertain. The objective of this study was to compare clinical outcomes of patients with successful (TICI $2 \mathrm{~b} / 3$ ) and failed (TICI 0/2a) reperfusions during endovascular mechanical thrombectomy for low NIHSS large vessel occlusion stroke.

Materials and methods We conducted a retrospective analysis on all patients who underwent stent retriever and/or aspiration thrombectomy between January 2012 to May 2017 at the Gates Vascular Institute in Buffalo, NY. Thirty-one patients with a large vessel occlusion and NIHSS $\leq 6$ were identified. These patients were divided into two groups, those who received TICI $2 b / 3$ recanalization and those who received TICI 0/2a. Demographic, procedural and outcome data was collected. Occurrence of vasospasm, thromboembolic complications, symptomatic hemorrhage, discharge NIHSS, hospital stay and outcome at 90 days were compared between the two groups.

Results Of the 31 thrombectomies, 26 were TICI 2b/3 while 5 were TICI $0 / 2 \mathrm{a}$. The mean age of patients who attained successful reperfusion was $68.35 \pm 11.88$ years with 11 males $(42 \%)$ whereas that of failed patients was $65 \pm 15.20$ years 